\title{
Congenital Abnormalities Induced by Heterologous Antisera Directed Against Rat Kidney Glycoproteins Isolated by Concanavalin A Affinity Chromatography
}

\author{
CHRISTOPHER C. K. LEUNG, CHUNG-HO HUNG, BILLY G. HUDSON, ROBERT L. BRENT, AND \\ RICHARD C. COTTON \\ Department of Anatomy, University of Kansas Medical Center, Kansas City, Kansas and Department of Pediatrics, \\ Jefferson Medical College, Thomas Jefferson University, Philadelphia, Pennsylvania USA
}

\begin{abstract}
Summary
It has been well established that heterologous antisera against whole rat kidney homogenate when injected into pregnant rats during the embryonic organogenetic period may induce abnormal embryonic development. Attempts were made to isolate the active components from soluble rat kidney extract by ammonium sulfate precipitation, anion-exchange chromatography, and concanavalin A-Sepharose 4B affinity chromatography. The glycoproteins isolated were capable of stimulating the production of potent rabbit antisera. When injected ip into the 9th day pregnant rats, these antisera induced embryonic death, congenital abnormalities, and fetal growth retardation. Eighty-four surviving fetuses were examined, all of them were malformed. The most frequently observed congenital defects were anophthalmia and microphthalmia. Attempts were made to analyze the glycoprotein fraction by discontinuous and sodium dodecyl sulfate (SDS)-polyacrylamide gel electrophoresis. The results indicate that the glycoproteins were of high molecular weight and could be dissociated by SDS into a multitude of molecules or subunits. Although double immunodiffusion indicated that there were one major and two minor antigens in the glycoprotein fraction, attempts to identify the antigens as to their size by analytical gel electrophoresis have not been successful. Electron microscopic study seemed to suggest that the glycoproteins might tend to aggregate to form particulates. The underlying mechanism whereby the antisera to these glycoproteins induce abnormal embryonic development is not understood. The hypotheses to explain the possible sites of teratogenic antibody interaction are discussed.
\end{abstract}

\section{Speculation}

Heterologous antibodies are known to be transmitted from the mother to the fetus. The data indicate that the antigens which stimulate the production of teratogenic antibodies are glycoproteins. Recently, it has been demonstrated by other developmental biologists that each tissue contains a specific aggregation factor that ligates cells of that particular tissue. These aggregation factors are glycoproteins. It is possible that a population of heterologous antibodies directed against rat kidney glycoproteins may crossreact with some aggregation factors and, thus, interfere with cell-cell interaction at the time of histogenesis resulting in abnormal embryonic development.

The production of congenital malformations following injection of heterologous antisera directed against whole rat kidney homogenate into pregnant rats was first reported by Brent et al. (7). This finding has been repeatedly confirmed and extended by other investigators $(2,9,12,20,27)$. The underlying mechanism whereby teratogenic kidney antisera induce abnormal embryonic development is not understood, although the responsible agents are known to be immunoglobulin $\mathrm{G}$. It appears that the induction of congenital malformations by these immunoglobulins does not depend on complement and other nonspecific immunologic mediators (5). The rat kidney antigens which elicit the production of these teratogenic antibodies have neither been defined nor characterized since the original finding in 1961 (8). This communication reports that rat kidney glycoproteins isolated by concanavalin $\mathrm{A}$ (Con $\mathrm{A}$ ) affinity chromatography elicit the production of potent teratogenic antibodies.

\section{MATERIALS AND METHODS}

TIMING OF PREGNANCY

Randomly bred Wistar rats were mated for $14 \mathrm{hr}$ overnight. Females that had been inseminated were considered to be $0 \mathrm{hr}, 0$ day pregnant at $9 \mathrm{AM}$ the next morning or at the beginning of the lst day of pregnancy. Rats were housed in stainless steel cages and given food (Purina Mouse Chow) and water ad libitum.

\section{ISOLATION OF GLYCOPROTEINS}

Wistar rats of both sexes weighing 200-300 g were perfused with isotonic phosphate-buffered saline (PBS), pH 7.3. Kidneys were removed, decapsulated, and immediately frozen at $-60^{\circ} \mathrm{C}$. Each experiment utilized 100 frozen kidneys and the entire isolation procedure was performed in the cold at $4^{\circ} \mathrm{C}$. Kidneys were homogenized in PBS ( $2 \mathrm{ml} /$ kidney) in a Virtis " 45 " homogenizer (Virtis Company, New York) for $20 \mathrm{~min}$. The homogenate was passed through a stainless steel sieve $(40 \mathrm{mesh})$ to remove large pieces of connective tissue and tissue debris. The filtrate was recovered and centrifuged $105,000 \times g$ for $1 \mathrm{hr}$. The resultant clear supernatant was recovered; the residual pellet was reextracted with PBS and the homogenate was centrifuged as described in the first extraction. The resultant supernatant was pooled with the supernatant obtained from the first extraction. The pooled supernatant was adjusted with ammonium sulfate to make a $40 \%$ solution of $\left(\mathrm{NH}_{4}\right)_{2} \mathrm{SO}_{4}$ and allowed to equilibrate overnight. Protein precipitates were sedimented by centrifugation at $12,000 \times \mathrm{g}$. After discarding the supernatant, the precipitates were redissolved with minimal amount of PBS. The protein solution was then dialyzed against PBS overnight and against $20 \mathrm{mM}$ sodium phosphate buffer, $\mathrm{pH} 8.0$ for 3 days with multiple changes of buffer in preparation for anion-exchange chromatography. The dialysate was concentrated to about $25 \mathrm{ml}$ by an Amicon ultrafiltration unit fitted with a PM 10 membrane. Anion exchange diethylaminoethyl cellulose (DE 52) was obtained from Whatman (England). Buffer equilibration, removal of fines, and column packing were 
performed according to the instructions provided by the manufacturer. The concentrate from the Amicon ultrafiltration unit was clarified by centrifugation at $2000 \times \mathrm{g}$. The resultant supernatant was applied onto the DE 52 column. The absorbance of the effluent was determined at $280 \mathrm{~nm}$ by a Hitachi spectrophotometer. After the passthrough peak, a crude fraction was obtained by utilizing one-step elution method with $0.3 \mathrm{M} \mathrm{NaCl}$ (Fig. 1). The crude fraction thus obtained was subsequently dialyzed for 2 days against $20 \mathrm{mM}$ sodium phosphate buffer, $\mathrm{pH} 7.0$, containing $0.9 \%$ $\mathrm{NaCl}$ with multiple changes of buffer. The dialysate was concentrated to about $25 \mathrm{ml}$ by an Amicon ultrafiltration unit fitted with a PM 10 membrane. The concentrate was clarified by centrifugation at $2000 \times g$. The resultant supernatant was applied onto the Con A-Sepharose 4B column prepared as follows. Con A covalently bound to Sepharose 4B was obtained from Pharmacia (Uppsala, Sweden). One $\mathrm{ml}$ of packed Sepharose 4B contained approximately $10 \mathrm{mg}$ of Con A. Fifty $\mathrm{ml}$ of Con A-Sepharose 4B was equilibrated with $20 \mathrm{mM}$ sodium phosphate buffer $\mathrm{pH} 7.0$ containing $0.9 \% \mathrm{NaCl}$ and packed into a glass column $(15 \times 300$ $\mathrm{mm}$ ). The equilibrated protein concentrate was allowed to pass through the Con A-Sepharose 4B column at a flow rate of $5 \mathrm{ml}$ / hr. The column was then washed with the same buffer until the absorption of the effluent at $280 \mathrm{~nm}$ decreased to almost the buffer level. The absorbed glycoproteins were eluted by the addition of the same buffer containing $50 \mathrm{mM} \alpha$-methyl-D-mannoside (Fig. 2 ). The eluted glycoproteins were dialyzed against distilled water for 3 days with multiple changes of distilled water and then lyophilized.

\section{PRODUCTION OF ANTISERA}

New Zealand white female rabbits weighing about $2.5 \mathrm{~kg}$ each were utilized for the production of antisera by the method previously reported (18). Forty $\mathrm{mg}$ of lyophilized glycoproteins were reconstituted with $10 \mathrm{ml}$ of PBS. One-half $\mathrm{ml}$ of the glycoproteins preparation was emulsified with equal volume of complete Freund's adjuvant (Difco) for each immunization. Three rabbits were utilized and all were initially immunized once in the foot-

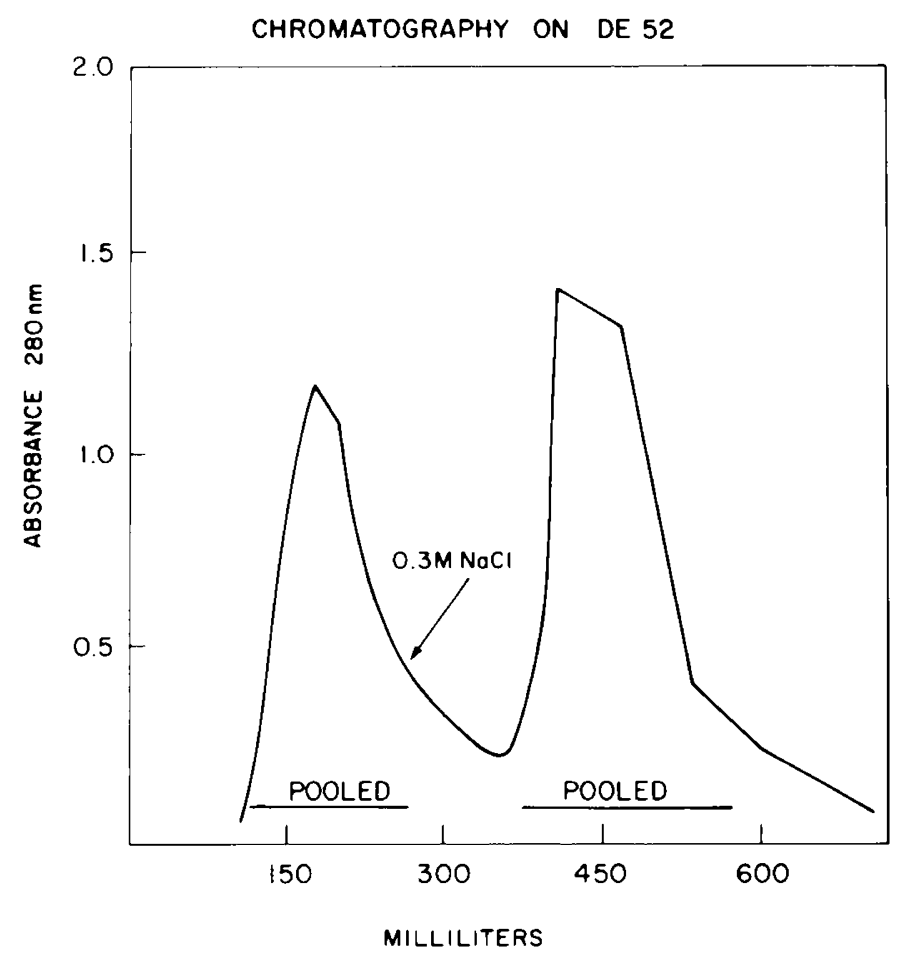

Fig. 1. A profile of DE 52 chromatography of proteins precipitated at $40 \%$ ammonium sulfate saturation. Other details are in Materials and Methods. The passthrough region and the eluate resulting from the addition of $0.3 \mathrm{M} \mathrm{NaCl}$ were pooled separately as indicated.

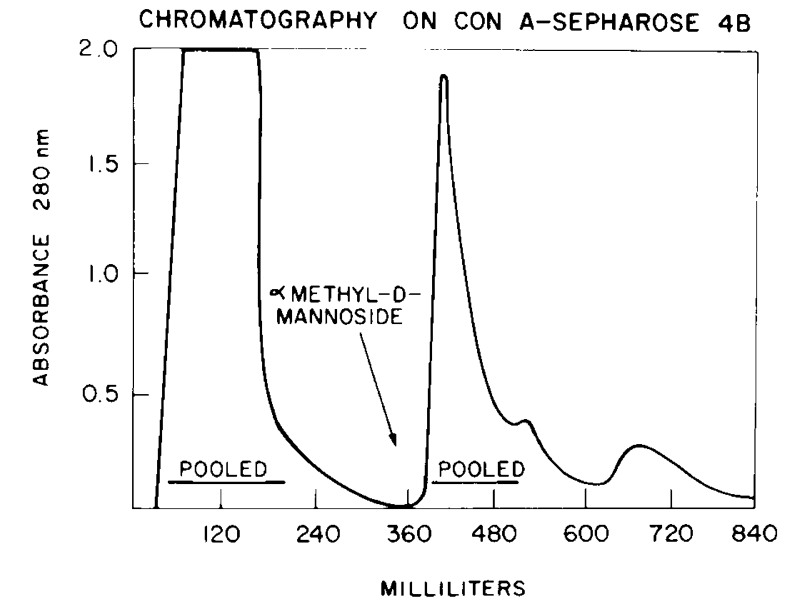

Fig. 2. Con A-Sepharose 4B affinity chromatography of proteins eluated off the DE 52 column using $0.3 \mathrm{M} \mathrm{NaCl}$ (Fig. 1). Glycoproteins were eluted by the addition of $\alpha$ methyl-D-mannoside. Passthrough region and eluted glycoproteins were pooled separately as indicated.

pads. Subsequent subcutaneous multiple-site injections were given weekly for 5 more wk. Rabbits were bled weekly from the central artery of the ear after the fourth immunization. One wk after the last injection, the rabbits were exsanguinated by cardiac puncture. Sera from multiple bleedings of each rabbit were pooled, decomplemented at $56^{\circ} \mathrm{C}$ for $30 \mathrm{~min}$, analyzed by double immunodiffusion, and stored at $-20^{\circ} \mathrm{C}$. Rabbit antisera were similarly produced against the following antigens: 1) lyophilized proteins obtained from the passthrough peak from the DE-52 cellulose column; 2) lyophilized proteins obtained from the passthrough peak from the Con A-Sepharose 4B column; and 3) Con A (Sigma). The amount of antigens injected into each rabbit was $5 \mathrm{mg}$ / immunization.

\section{BIOASSAY OF ANTISERA}

The biologic effects of the various antisera on embryonic development were tested in the following manner. On the 9 th day of gestation, pregnant rats were injected ip with various dosages of pooled rabbit antisera. Control pregnant rats were injected similarly with preimmunization rabbit serum and rabbit antiserum against Con A. All rats were anesthetized with sodium pentobarbital $(30 \mathrm{mg} / \mathrm{kg})$ before ip injection. The mothers were killed on the 22 nd day of gestation and the fetuses were delivered by caesarean section. The fetuses were examined grossly, weighed, and fixed in Bouin's fixative for dissection. The incidence of malformations was determined by the cross-sectional technique described by Wilson (29).

\section{IMMUNODIFFUSION}

Double immunodiffusion was performed in petri dishes containing 1.0\% agar gel in PBS, $\mathrm{pH}$ 7.3. Merthiolate was added as a bacteriostatic agent. Each well was $2 \mathrm{~mm}$ in diameter. All wells were $5 \mathrm{~mm}$ from each other, center to center. The gel dishes were kept in an humidified chamber at room temperature and observed for 2-3 days. After optimum precipitin lines had developed, the gels were removed and washed in PBS for 3 days, dried, and stained with $1 \%$ amido black. After destaining in methanol the precipitin lines were photographed.

\section{ACRYLAMIDE GEL ELECTROPHORESIS}

Attempts to identify the antigens within the glycoprotein fraction eluted from Con A column were first made by utilizing discontinuous polyacrylamide gel electrophoresis. The procedure used was essentially the same as described by Davis (10), but without upper stacking gel. One hundred ug of protein were subjected to electrophoresis in 5\% gel. Glycoprotein samples were 
dissolved in $0.05 \mathrm{M}$ Tris- $\mathrm{HCl}, \mathrm{pH} 8.2$, and adjusted to $15 \%(\mathrm{v} / \mathrm{v})$ glycerol and $0.1 \%$ bromophenol blue. Electric current was maintained at $5 \mathrm{~mA} /$ tube. At the completion of the run, the gels were removed from the tubes, rinsed with distilled water, and sliced with a manual slicer (Buchler Searle Instrument) with the blades set at $2 \mathrm{~mm}$ apart. Duplicate gels were stained for proteins with $0.05 \%$ Coomassie blue. The proteins residing within the unstained $2 \mathrm{~mm}$ sliced gel segments were allowed to react with rabbit antiserum against the glycoproteins eluted from Con A column according to the method described by Puszkin et al. (23). The 2$\mathrm{mm}$ thick gel segments were aligned consecutively at regular distances on a glass slide. Warmed agar $\left(40^{\circ} \mathrm{C}\right)$ was added gently over the gel slices. After the agar had hardened, wells were bored manually and filled with antiserum.

Second attempts to identify the antigens responsible for eliciting teratogenic antibodies were made by SDS polyacrylamide gel electrophoresis. Glycoprotein samples were dissolved in $0.1 \mathrm{M}$ phosphate buffer, $\mathrm{pH} 7.0$ containing $2 \%$ SDS and incubated at room temperature overnight. At the end of incubation, sample solutions were adjusted to $15 \%(\mathrm{v} / \mathrm{v})$ glycerol and $0.01 \%$ bromophenol blue. Electrophoresis was carried out according to the procedure described by Weber and Osborn (28) using 5\% polyacrylamide containing $0.1 \%$ SDS. One hundred ug of protein were layered on top of the gel and electrophoresed with a current of 8 $\mathrm{mA} /$ tube for $5 \mathrm{~h}$. At the end of electrophoresis, the gels were removed, sliced into $2-\mathrm{mm}$ segments and allowed to react with rabbit antiserum against the glycoproteins eluted from Con A column as described for gels after discontinuous polyacrylamide gel electrophoresis. Duplicate gels were stained for protein with $0.05 \%$ Coomassie blue. Standard SDS-polyacrylamide gel electrophoresis was simultaneously run utilizing protein standards myosin, $\beta$-galactosidase, bovine serum albumin, ovalbumin, and chymotrypsin. Mixture of these proteins were prepared by dissolving $1 \mathrm{mg}$ of each proteins in $1 \mathrm{ml}$ of $0.1 \mathrm{M}$ phosphate containing $2 \%$ SDS, $6 \mathrm{M}$ urea, and $2 \% \beta$-mercaptoethanol.

\section{ELECTRON MICROSCOPY}

The lyophilized glycoproteins eluted from Con A column were fixed in $2 \%$ glutaraldehyde, postfixed in osmium tetroxide, dehydrated in graded alcohols through propylene oxide, and embedded in Epon 812. Ultrathin sections, stained with uranyl acetate and lead citrate, were examined with a RCA electron microscope.

\section{RESULTS}

The results of the chromatographic steps to isolate the rat kidney glycoproteins after PBS-extraction, ultracentrifugation, and ammonium sulfate precipitation are illustrated in Figures 1 and 2.

The results of testing for biologic effects of the antisera on embryonic development are summarized in Table 1 . When administered to pregnant rats on the 9th day of pregnancy, the antisera raised against the glycoproteins obtained by Con $\mathrm{A}$ affinity chromatography were found to be very potent embry- opathic agents, inducing embryonic death, various congenital malformations, and fetal growth retardation. Ip injection of 0.12 $\mathrm{ml} / 100 \mathrm{~g}$ of pregnant rat induced abnormal embryonic development in all of the surviving fetuses. The spectrum of malformations was somewhat similar to that reported previously by Brent (7) using antisera against whole rat kidney homogenate or antisera against chorioallantoic placentas (6). The biologic effects of the antisera were dose-dependent. A dosage of either 5 or $2.5 \mathrm{ml} / \mathrm{kg}$ of pregnant rat was lethal to all the embryos. The most frequently observed congenital defects were anophthalmia (Fig. 3) and microphthalmia. Practically $100 \%$ of all surviving fetuses were either anophthalmic or microphthalmic. A total of 34 pregnant rats were injected with various control sera. Preimmunization rabbit serum and antisera raised against Con $\mathrm{A}$ or other passthrough protein fractions appeared to have no effect on embryonic development even when given at a high dose $(10 \mathrm{ml} / \mathrm{kg}$ pregnant rat $)$.

The result obtained from discontinuous polyacrylamide gel electrophoresis of the kidney glycoproteins suggested that these glycoproteins were of very high molecular weights. Even at $5 \%$ gel porosity, the glycoproteins did not penetrate into the separating gel (Fig. 4A). When the unstained $2-\mathrm{mm}$ gel segments were allowed to react with the antiserum against glycoproteins eluted from Con A column, there were no reactivity for all the segments except the first $2-\mathrm{mm}$ gel segment. The stained gel (Fig. 4A) confirmed that the glycoproteins remained at the top of the gel column. SDS-polyacrylamide gel electrophoresis of the same glycoproteins showed that there were at least 18 discernible bands (Fig. 4B). However, when the unstained 2-mm gel segments were allowed to react with the antiserum, no specific immunoreactivity could be observed, even though the plates were kept under observation in a humidified chamber, for as long as 2 wk.

The results of double immunodiffusion analysis (Fig. 5) indicated that there was one major precipitin band together with two barely discernible minor ones. These three bands appeared not to be the products between antibodies and rat serum proteins. The results seemed to indicate that the three antigens in the glycoprotein fraction were not components of rat serum proteins. This has been confirmed by absorbing the glycoproteins antiserum with normal rat serum. Immunodiffusion between the absorbed antiserum and the glycoproteins resulted in the three similar bands. Reactivity between the absorbed antiserum and the PBS rat kidney homogenate also produced three bands.

Electron microscopic examination of the glutaraldehyde-fixed glycoproteins suggested that these glycoproteins might have aggregated to form some kind of particulates (Fig. 6). The sizes of these particulates appeared to be smaller than ribosomes.

\section{DISCUSSION}

Since the discovery of this interesting model in which abnormal embryonic development can be induced by heterologous antibodies, very little progress has been made in the past $18 \mathrm{yr}$ in the area of defining the antigen(s) that elicits the production of teratogenic antibodies. This apparent slow progress is perhaps primarily due to the inherent difficulties involved in this kind of

Table 1. Effects of various antisera against rat kidney antigens on embryonic development

\begin{tabular}{|c|c|c|c|c|c|c|}
\hline \multirow[b]{2}{*}{ Rabbit antiserum } & \multirow[b]{2}{*}{$\begin{array}{l}\text { No. of } \\
\text { liters }\end{array}$} & \multirow[b]{2}{*}{$\begin{array}{c}\mathrm{Ml} \\
\text { antiserum } / \mathrm{kg} \\
\text { pregnant rat (ip) }\end{array}$} & \multirow[b]{2}{*}{$\begin{array}{l}\quad \% \text { of } \\
\text { embryonic } \\
\text { resorption }\end{array}$} & \multicolumn{2}{|c|}{ Surviving fetuses } & \multirow[b]{2}{*}{$\begin{array}{l}\text { Mean fetal } \\
\text { weight at term } \\
(\mathrm{g} \pm \mathrm{SD})\end{array}$} \\
\hline & & & & No. & $\begin{array}{l}\% \text { having } \\
\text { malformations }\end{array}$ & \\
\hline \multirow{3}{*}{$\begin{array}{l}\text { Antisera to glycoproteins isolated by Con A } \\
\text { affinity chromatography }\end{array}$} & 3 & 5 & 100 & & & \\
\hline & 3 & 2.5 & 100 & & & \\
\hline & 8 & 1.2 & 14 & 84 & 100 & $3.42 \pm 0.51$ \\
\hline $\begin{array}{l}\text { Antisera to passthrough proteins (DE } 52 \text { col- } \\
\text { umn) }\end{array}$ & 8 & 10 & 6.2 & 90 & 0 & $4.60 \pm 0.62$ \\
\hline $\begin{array}{l}\text { Antisera to passthrough proteins (Con A-Seph- } \\
\text { arose } 4 \mathrm{~B} \text { column) }\end{array}$ & 8 & 10 & 5.7 & 83 & 2.4 & $4.81 \pm 0.43$ \\
\hline Antisera to Con $\mathrm{A}$ & 9 & 10 & 12.1 & 88 & 1.1 & $4.68 \pm 0.57$ \\
\hline Preimmunization rabbit serum & 9 & 10 & 6.5 & 101 & 1.0 & $4.65 \pm 0.54$ \\
\hline
\end{tabular}




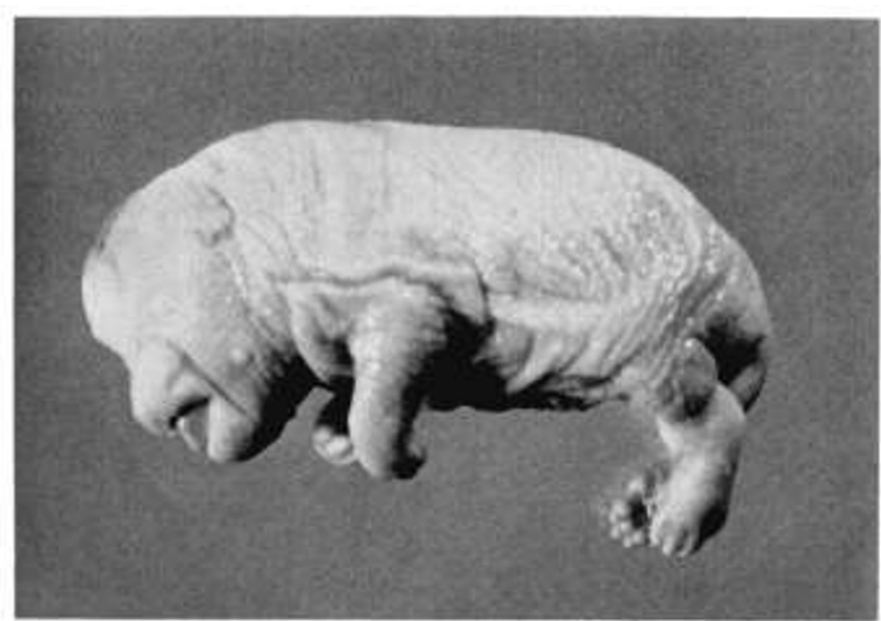

Fig. 3. A small encephalocele and anophthalmia in a term fetus whose mother was injected on the 9th day of gestation with $0.25 \mathrm{ml}$ of rabbit antiserum raised against the glycoproteins isolated by Con $\mathrm{A}$ affinity chromatography.

teratogenic model. There is no in vitro method to substitute the time-consuming bioassay using the incidence of malformations as the end point. That is, to inject every fraction or subfraction into rabbits for 6-7 wk is necessary in order to produce antisera. The resulting antisera have to be tested in time-pregnant rats in order to determine which fraction or subfraction contains the active molecule(s) after examination of dissected fetuses. This procedure involving the production of an era and subsequent bioassay of the antisera is the only method available at this time. Further complicating the situation is the fact that some rabbits do not respond to antigenic stimulation as well as others, and therefore, may produce very low titers of antibodies. In order to ensure meaningful bioassay, several rabbits must be immunized with the same antigenic material and utilize only hyperimmune sera of proven high antibody titer. Each purification step depends entirely on the outcome of antibody production and the subsequent effects of the antisera on embryonic development.

Although the glycoproteins isolated are not immunogenically pure (one major and two minor bands), the purification procedure reported in this communication has been repeated and confirmed several times by bioassay and double immunodiffusion analysis. Further purification will be attempted by utilizing gel filtration, hydrophobic chromatography, and isoelectric focusing technique. Unfortunately, there have been problems in identifying the antigens in the polyacrylamide gel electrophoresis system, future antigenic detection in monitoring various purification steps may have to rely on double immunodiffusion test.

It has been demonstrated in this report that partially purified glycoprotein fraction obtained from PBS extraction of rat kidney, followed by ultracentrifugation, ammonium sulfate precipitation, DE 52 anion-exchange, and Con A affinity chromatography contained the active molecules responsible for the production of potent teratogenic and embryotoxic rabbit antisera. This fraction seemed to consist of very large molecular weight molecules as suggested by the results of the discontinuous gel electrophoresis experiment. The glycoproteins could be easily dissociated in SDS and appeared to contain a multiple of different sizes of molecules or subunits. Although double immunodiffusion analysis indicated that there were one major and two minor precipitin bands, attempts to identify the antigens have not been successful by SDSpolyacrylamide gel electrophoresis.

It is well documented that abnormal embryonic development may be induced experimentally by heterologous antisera directed against whole rat kidney homogenate. Understanding of the underlying mechanism of antibody-mediated abnormal embryonic development is very limited. Three hypotheses have been proposed by Slotnick and Brent (25). They are: 1) a secondary effect of antibodies on embryonic development due to immunologic diseases of the injected mother, 2) induction of chorioallantoic or yolk sac placental dysfunction by antibodies, and 3) a direct effect of antibodies on the embryo proper.

The first hypothesis assumes that birth defects are the results of maternal immunologic diseases. For example, heterologous anti-

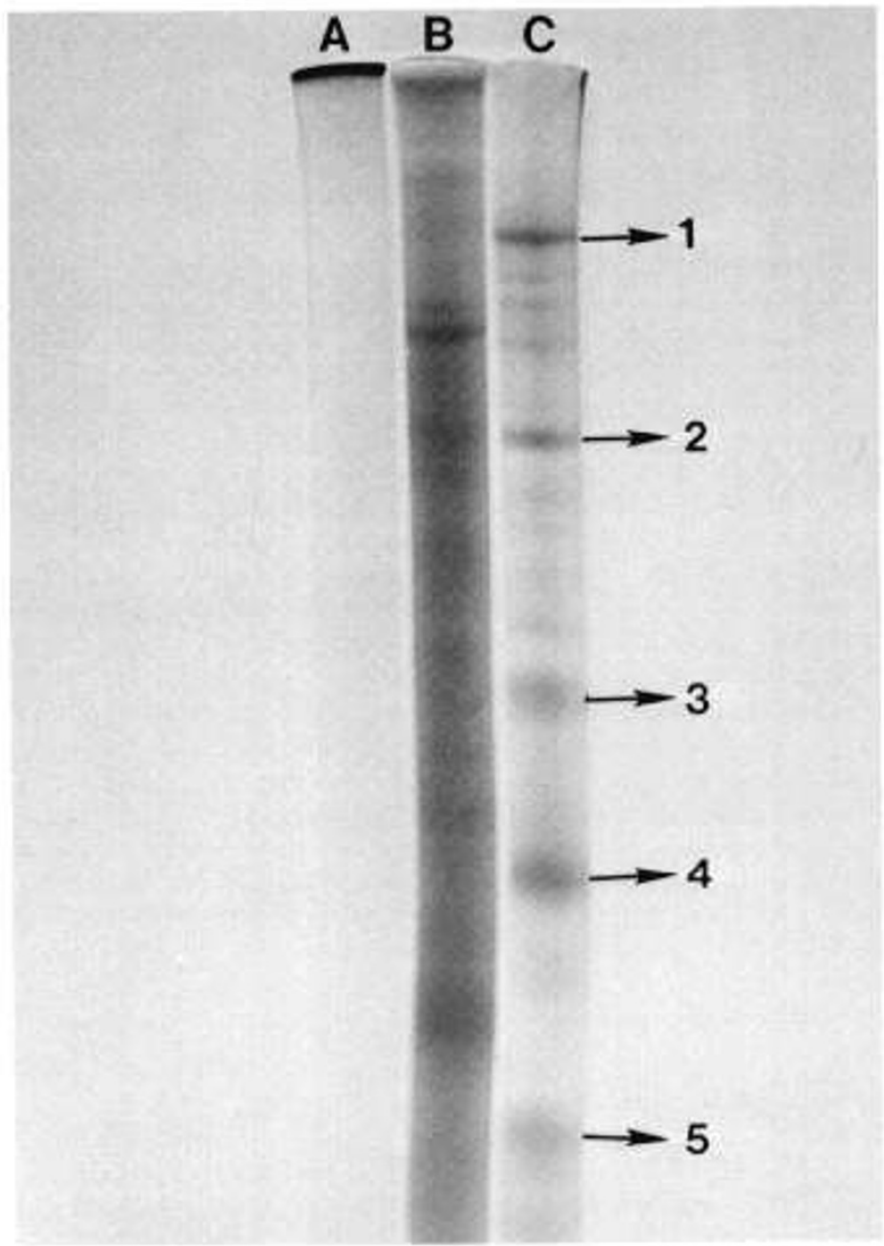

Fig. 4. $A$ : discontinuous polyacrylamide gel electrophoresis of the glycoproteins eluted off the Con A affinity column. $B$ : SDS-polyacrylamide gel electrophoresis of the same glycoproteins. $C$ : SDS-polyacrylamide gel electrophoresis of protein standards: 1 , myosin, molecular wt 212,000; 2 , $\beta$-galactosidase, molecular wt 135,000; 3, bovine serum albumin, molecular wt 69,$000 ; 4$, ovalbumin, molecular wt 43,000 ; and 5 , chymotrypsinogen, molecular wt 25,700 .

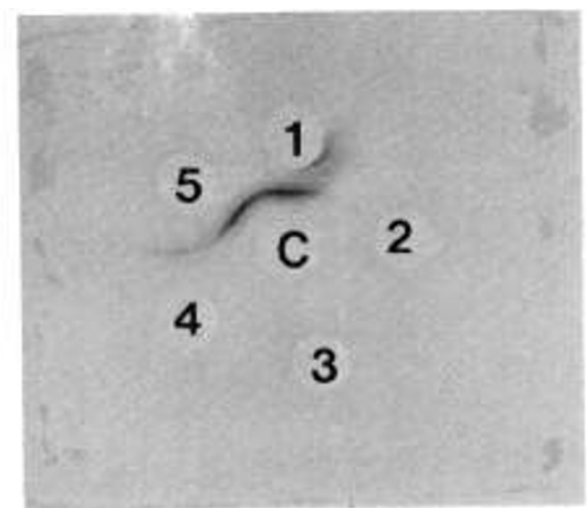

Fig. 5. Antiserum against glycoproteins isolated by Con A affinity chromatography-wells $I$ and 5 ; glycoproteins isolated by Con A affinity chromatography-wells $C$ and 4; normal rat serum-well 2 ; well 3empty. 


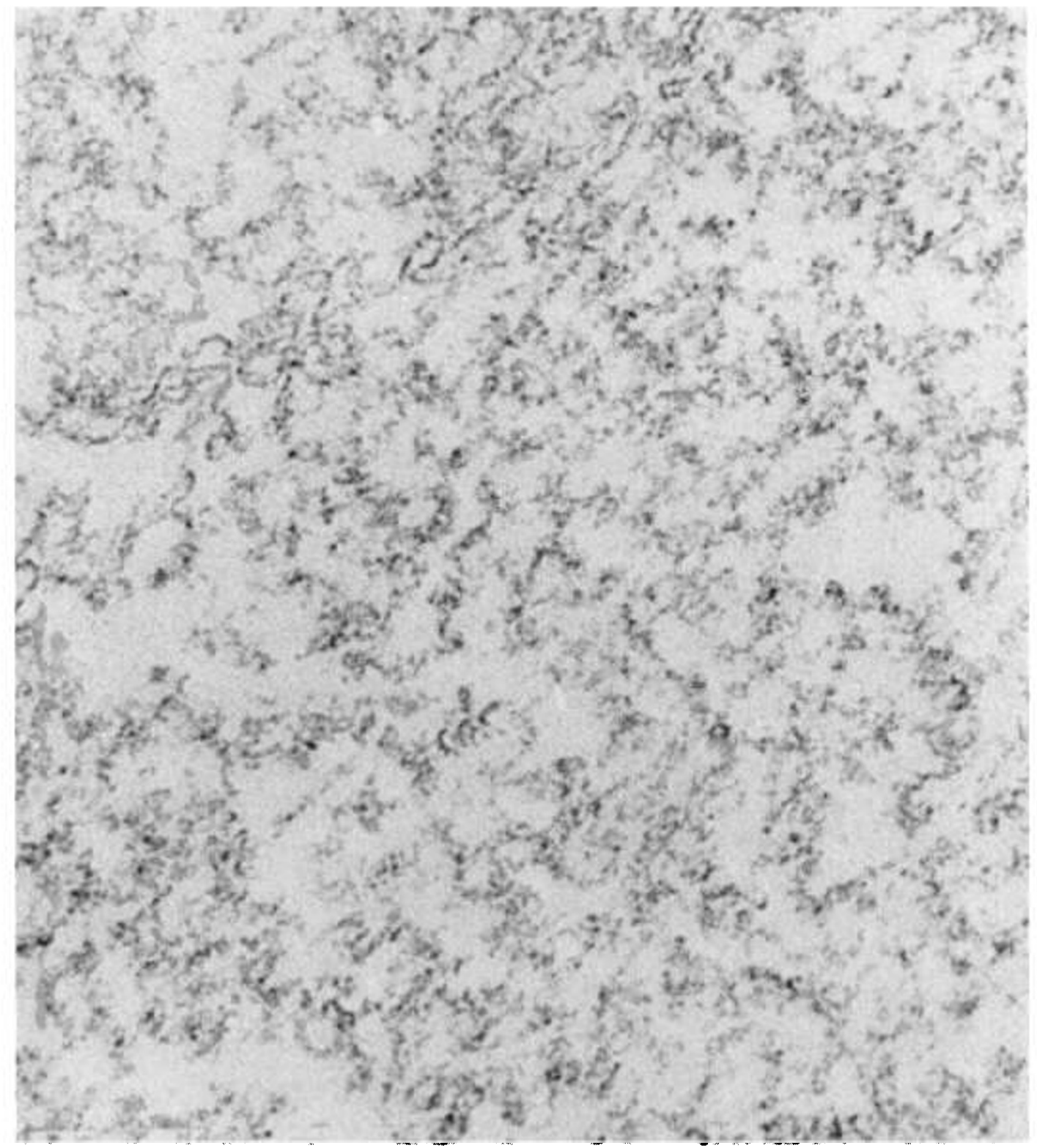

Fig. 6. Electron micrograph of lyophilized glycoprotein preparation. X 45,000.

sera directed against rat kidney homogenate are known to be nephrotoxic (26) and would induce "Masugi" nephritis that resembles the pathology of certain human glomerulonephritis. Thus, teratogenesis observed with kidney antisera could be a result of maternal immunologic kidney disease. However, strong evidence has been presented $(17,18)$ to support the view that teratogenicity and nephrotoxicity of kidney antisera are of separate biologic properties. The nephrotoxicity of the antisera did not parallel their teratogenicity $(17,18)$. It was demonstrated that antisera directed against PBS-soluble rat kidney antigens were teratogenic but not nephrotoxic (18). These data suggest that abnormal embryonic development induced by heterologous kidney antisera does not result from maternal glomerulonephritis but do not, however, exclude the possibility that malformations could result from other maternal immunologic diseases.

The second hypothesis considers the possible dysfunction of chorioallantoic or yolk sac placenta caused by heterologous kidney antisera. In the literature, there is no reported data to indicate that heterologous kidney antisera impair the biologic functions of the chorioallantoic or yolk sac placenta, although previous studies demonstrated that kidney antibodies were found to localize within the visceral yolk sac endodermal cells $(17,18)$.

With the present knowledge on maternal transfer of both ho- mologous and heterologous antibodies to the fetus, the hypothesis that considers abnormal embryonic development induced by heterologous teratogenic antibodies due to a direct action on the embryo proper is becoming more attractive although the other two hypotheses cannot be ruled out. The question whether homologous or heterologous antibodies ever reach the embryo during the period of organogenesis is of obvious importance. It is known that antibodies are transmitted from the mother to the fetus in the last third of pregnancy (see Brambell (4) for review). It is also well established that heterologous IgG can be transported across the maternofetal barrier in the direction of mother to the fetus in rodents and rabbits $(13,15,16,24)$. Heterologous IgG are known to be transmitted similarly as homologous IgG, Although the rates of transmission may be different. However, all these previous studies were performed at later stage of gestation, that is, beyond the period of organogenesis. The presence of maternal immunoglobulins in the mouse embryo proper examined from the 6thllth day of gestation (including the organogenetic period) was recently first demonstrated by immunoperoxidase method (3). Because heterologous antibodies are known to be similarly transmitted as homologous antibodies from the mother to the fetus at a later stage of gestation and because homologous maternal antibodies are present during the organogenetic period in the mouse 
embryo, it is difficult to perceive that heterologous antibodies would be selectively excluded from reaching the embryo during the organogenetic period. Therefore, it is very likely that heterologous kidney antibodies will be transmitted to the embryo during the organogenetic period.

Suggestions have been made resulting from studies on histogenetic aggregation of cells that specific cell contacts are mediated by interactions of specific macromolecules on cell surfaces. These cell ligands may play an important role in cell recognition and selective adhesiveness and, therefore, in the assembly and organization of cells into tissues and organs $(1,11,19,21,22)$. Based on data obtained from studies on aggregation of dissociated chick neural retina cells and other tissues, it was shown that each tissue contains a specific aggregation factor that ligates cells of that particular tissue. It has been shown that aggregation factors are glycoproteins. In fact, a glycoprotein aggregating factor has been isolated from chick embryonic neural retina cells by Hausman and Moscona (14). The present data indicate that the active antigenic fraction isolated from rat kidney homogenate binds to Con A-Sepharose 4B. The bound antigens can be eluted with $\alpha$ methyl-D-mannoside. Thus, these data indicate that the antigens which stimulate the production of teratogenic antibodies are glycoproteins. One may speculate that it is possible that a population of antibodies directed against these glycoproteins may crossreact with some aggregation factors and, thus, interfere with cell-cell interaction at the time of histogenesis resulting in abnormal embryonic development.

\section{REFERENCES AND NOTES}

1. Balsamo, J., and Lilien, J: The binding of tissue-specific adhesive molecules to the cell surface. A molecular basis for specificity. Biochem.. 14: 167 (1975).

2. Barrow. M. V., and Taylor, W. J.: The production of congenital defects in rats using antisera. J. Exp. Zool, 176: 41 (1971).

3. Bernard, O., Ripoche, M. A., and Bennett, D.: Distribution of maternal immunoglobulins in the mouse uterus and embryo in the days after implantation. J. Exp. Med., 145: 58 (1977)

4. Brambell. F.W. R.: The transmission of passive immunity from mother to young In: Frontiers of Biology. Vol. 18. (North-Holland Publishing Company. Amsterdam. 1970).

5. Bragonier, J. R., Frank, M. M., and Brent, R. L.: Production of congenital malformations using tissue antisera VIII. Effectiveness of reduced, alkylated. and digested anti-kidney antibodies. J. Immun. 105: 1175 (1970).

6. Brent. R. L.: Production of congenital malformations using tissue antisera. III Placental antiserum. Proc. Soc. Exp. Biol. Med., 125: 1024 (1967).

7. Brent, R. L.: The production of congenital malformations with tissue antibodies. II. The spectrum and incidence of malformations following the administration of kidney antiserum to the pregnant rat. Am. J. Anat., 115: 525 (1964)

8. Brent, R. L., Averich, E., and Drapiewski, V. A.: Production of congenital malformations using tissue antibodies. I. Kidney antisera. Proc. Soc. Exp. Biol. Med., 106: 523 (1961)

9. David. G.. Mercier-Parot, L.. and Tuchmann-Duplessis, H.: Action teratogene d'heteroanticorps tissulaires. I. Production de malformations chez le rat par action d'un serum antirein. C. R. Soc. Biol., 157: 939 (1963).
10. Davis, B. J.: Disc electrophoresis - II. Method and application to human serum proteins. Ann. N. Y. Acad. Sci., 121: 404 (1964).

11. Garber, B. B., and Moscona, A. A.: Reconstruction of brain tissue from cell suspensions. Il. Specific enhancement of aggregation of embryonic cerebral cells by supernatant from homologous cell cultures. Dev. Biol., 27: 235 (1972).

12. Gebhardt, D. O. E., Baart de la Faille-Kuyper, E. H., and Nagel, J.: The embryolethality and localization of antikidney serum in the pregnant mouse Mus musculus. Teratology, 3: 143 (1970).

13. Gitlin, D., and Morphis, L. G.: Systems of materno-foetal transport of $\gamma \mathrm{G}$ immunoglobulin in the mouse. Nature, 223: 195 (1969).

14. Hausman, R. E. and Moscona, A. A.: Purification and characterization of the retina-specific cell-aggregating factors. Proc. Nat. Acad. Sci. USA, 72: 916 (1975).

15. Hemmings, W. A., Jones, R. E., and Faulk, W. P.: Transport across the rabbi fetal yolk-sac of fractions of IgG from several mammalian species. Immunology. 28: 411 (1975).

16. Koch. D.. Boesman, M., and Gitlin, D.: Maternofoetal transfer $\gamma \mathrm{G}$ immunoglobulins. Nature, 216: 1116 (1967).

17. Leung, C. C. K., and Brent, R. L.: The production of congenital malformations using tissue antisera. X. Effectiveness of kidney antigens treated with neuraminidase or trypsin. Pediatr. Res., 6: 822 (1972).

18. Leung. C. C. K.. Urdaneta, A., Jensh, R. P., Jensen, M., and Brent, R. L. Evidence that different antibodies are involved in the production of immunologically induced teratogenesis and nephritis. J. Immunol., 113: 885 (1974).

19. Lilien, J. E.: Toward a molecular explanation for specific cell adhesion. Curr. Top. Develop. Biol. 4: 169 (1969)

20. Mikhailov, V. M.: Pathogenic action of nephrocytotoxic serum on embryonic development of albino rats. Biull. Eksp. Biol, Med., 63: 97 (1967).

21. Moscona, A. A.: Cell aggregation: properties of specific cell-ligands and thei role in the formation of multicellular systems. Develop. Biol., 18: 250 (1968)

22. Moscona, A. A.: Recombination of dissociated cells and the development of cell aggregates. In: E. N. Willmer: Cells and Tissues in Culture vol. 1, pp. 489-529. (Academic Press, New York, 1965).

23. Puszkin. S., Schook, W., Maimon, J., and Puszkin. E.: Immunologic identification of complex proteins resolved by sodium dodecyl sulfate polyacrylamide disc gel electrophoresis. Biochim. Biophys. Acta, 494: 144 (1977).

24. Slade, B. S., and Wild, A. E.: Transmission of human $\gamma$-globulin to.rabbit fetus and its inhibition by conjugation with ferritin. Immunology, 20: 217 (1971)

25. Slotnick, V.. and Brent, R. L.: The production of congenital malformations using tissue antisera. V. Fluorescent localization of teratogenic antisera in the maternal and fetal tissues of the rat. J. Immun. 96: 606 (1966).

26. Unanue, E. R., and Dixon, F. J.: Experimental glomerulonephritis: immunological events and pathogenetic mechanisms. In: F. J. Dixon and J. H. Humphrey: Advances in Immunology Vol. 6, pp. 1-90, (Academic Press, New York 1967).

27. Vaillancourt, P.. and McCallion, D. J.: Inhibitory effects of nephrotoxic antisera on the growth of rat fetuses. Am. J. Obstet. Gynecol.. 114: 255 (1972).

28. Weber, K., and Osborn, M.: The reliability of molecular weight determinations by dodecyl sulfate-polyacrylamide gel electrophoresis. J. Biol. Chem., 244. 4406 (1969).

29. Wilson, J. G.: Methods for administering agents and detecting malformations in experimental animals. In: J. W. Wilson and J. Warkany: Teratology: Principles and Techniques. pp. 251-277 (University of Chicago Press, Chicago, 1964).

30. The authors thank Dr. Albert Chapman for taking the electron micrograph.

31. The present address of C. C. K. Leung, Ph.D. is: Department of Anatomy, Louisiana State University Medical Center, Shreveport, Louisiana 71130 , USA.

32. Mr. Cotton is summer research fellow, first-year medical student.

33. This research was supported by National Institutes of Health grants HD 630 , HD 10603, HD 11805 and SO 1-RR-5373.

34. Received for publication March 12, 1979.

35. Accepted for publication May 15, 1979. 